\title{
Changing views of evolution and their consequences for psychology. From the Modern Synthesis to the Extended Synthesis, and beyond
}

\author{
ÁGNES SZOKOLSZKY ${ }^{1}$
}

Zsolt Palatinus ${ }^{2}$

"Our ignorance of the laws of variation is profound." Darwin (1859, 105, cited by di Frisco and Jaeger, 2019, p. 54.)

We must shift our focus away from the gene as the unit of selection to that of the whole organism.

Tautz 1992, in Noble, 2008, p.3001.

\begin{abstract}
Reductionist viewpoints have been increasingly replaced by complex systems viewpoints in biological theory and methodology since the turn of the millennium. This tendency has also been reflected in thinking about evolution. Just as the defining evolutionary synthesis of the 20th century - the Modern Synthesis - was born out of the integration of the most up-to-date knowledge of the times, so does a recently emerging new synthesis build on most recent genetic-epigenetic, genomic, eco-devo-evolutionary findings. The "Extended Synthesis" (Pigliucci \& Müller, 2010) builds on current understanding of genes, heredity, and multiple evolutionary processes. In this framework, an extended interpretation is offered based on the integration of evolutionary and ecosystem-level processes into the explanation of evolution. In this paper, we aim to review the paths leading to the Extended Synthesis. We aim to presenta historically embedded, concise overview of the major issues and developments related to the changing perspectives. The final point of the discussion eventually raises the question: How does psychology relate to the extended view of evolution?
\end{abstract}

\section{Keywords}

Darwinism, epigenetics, Modern Synthesis, Extended Synthesis, evo-devo, ecodevo, ecological niche construction

\section{Acknowledgments}

We would like to thank Dr. Gyula Hoffmann for useful comments on an earlier version of this manuscript and the encouragement to keep working on it. We also thank Dr. Catherine Read for valuable discussions and inspirations related to the topic and comments on the manuscript.

\footnotetext{
${ }^{1}$ University of Szeged, Institute of P sychology, szokolszky@gmail.com

${ }^{2}$ University of Szeged, Institute of Psychology,zsolt.palatinus@ gmail.com
} 